\title{
Left thigh pain with left lower abdominal discomfort
}

\author{
Yasuyuki Taooka*, Yuka Ide and Gen Takezawa \\ Department of General Medicine, Akiota Hospital, Hiroshima, Japan
}

86-year-old female, farmer came to our hospital complained of sudden onset of left thigh and left knee pan with left lower abdominal discomfort, when she was working in the field. She could not move her left leg because of severe pain. 2-month prior, she noticed short duration and repeated similar left thigh and knee pain without abdominal discomfort. She consulted her attending physician, and was treated with NSAIDs. In this time, her pain was continued longer, and complicated with abdominal discomfort. Physical examination showed tenderness in left lower quadrant of abdomen, but abdomen was soft with no rigidity and normal bowel sound. Her thigh and knee pain was severe and worsened with extension or abduction of left leg. Plain CT scan showed migrated small intestine into left obturator canal (Figure 1), showing obturator hernia (Figure 2). There was no evidence of peritonitis or ileus. Then, her symptoms and herniation



Figure 1. Plain pelvic CT [1]. Arrow head shows small intestine located in left obturator canal.

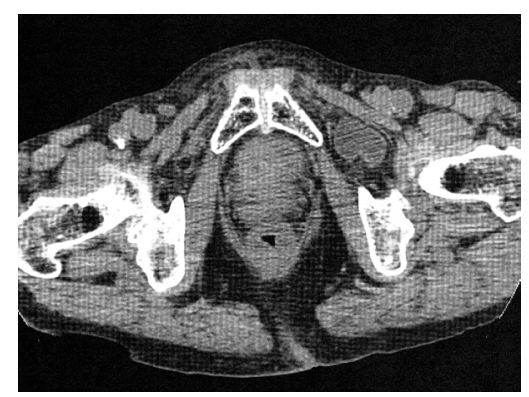

Figure 2. Plain pelvic CT [2]. Small intestine located outside of left obturator canal.

Copyright: (C2016 Taooka Y. This is an open-access article distributed under the terms of the Creative Commons Attribution License, which permits unrestricted use, distribution, and reproduction in any medium, provided the original author and source are credited. were spontaneously relived. To avoid the recurrence, obturator canal was surgical reinforced. After that, her repeated left thigh pain was discontinued.

Obturator hernia is rare but seen in thin, elderly females due to loss of protective fat-tissue in obturator canal $[1,2]$. Hernial sac stimulates obturator nerve and causing thigh pain radiating down to the inside of thigh or knee (Howship-Romberg sign) [1,3]. Thigh pain can be exacerbated by extension or abduction. In many cases, transientherniation repeats and finally complicates strangulation [1-4]. Usually, patients notice both abdominal pain and thigh pain, but in some cases only thigh repeat like this case. Therefore, CT scan is useful for early diagnosis [1-4].

\section{Conflicts of interest}

The authors declare that no competing interests.

\section{Author contributions}

YT and YI helped to obtain the clinical data, and contributed in critiquing the manuscript. All authors have read and approved the final manuscript.

\section{References}

1. Nakayama T, Kobayashi S, Shiraishi K, Nishiumi T, Mori S, et al. (2002) Diagnosis and treatment of obturator hernia. Keio J Med 51: 129-132.[Crossref]

2. Dundamadappa SK, Tsou IYY, Goh JSK (2006)Clinics in diagnostic imaging (107). Singapore Med J 47: 89-95.[Crossref]

3. Cai X, Song X, Cai X (2012) Strangulated intestinal obstruction secondary to a typical obturator hernia: A case report with literature review.Int J Med Sci 9: 213-215. [Crossref]

4. Chan PK, Ng TP, Lam YL (2012) Obturator hernia presenting as hip pain: A case report J Orthop Surg 20: 398-401.[Crossref]
Correspondence to: Yasuyuki Taooka, MD, FACP, Department of General Medicine, Akiota Hospital, Shimodomo-Gohchi 236, Akiota-Cho, YamagataGun, Hiroshima, 731-3622, Japan, Tel: +81-826-22-2299, Fax: +81-826-220623; E-mail: taooka-alg@umin.ac.jp

Key words: obturator hernia, elderly

Received: December 15, 2016; Accepted: December 20, 2016; Published: December 22, 2016 